Atıf - Citation: Ceylan, S. - Yiğitpaşa, N. T. 2021, “Güney İtalya Lecce'de Barok Dönem (XVII.

Yüzyıl) Kilise Bezemeleri", Amisos, 6/11, 202-219.

AMISOS / AMISOS

Cilt/Volume 6, Say1/Issue 11 (Aralı/ December 2021), ss./pp. 202-219

ISSN: 2587-2222 / e-ISSN: 2587-2230

DOI: 10.48122 /amisos.1009664

Özgün Makale / Original Article

Geliş Tarihi/Received: 14. 10. 2021

Kabul Tarihi/Accepted: 25. 11. 2021

\author{
GÜNEY İTALYA LECCE'DE BAROK DÖNEM (XVII. YÜZYIL) KİLİSE \\ BEZEMELERI ${ }^{*}$
}

\author{
BAROQUE PERIOD (XVII. CENTURY) CHURCHES DECORATIONS IN LECCE \\ SOUTH ITALY
}

\author{
Sinem CEYLAN - Nadire Tuba YİĞITPAŞA ${ }^{* *}$
}

\title{
$\ddot{O} z$
}

XVI. yüzyılın ikinci yarısında Trent Konsili'nde alınan kararlar doğrultusunda İtalya/Roma'da ortaya çıkan Barok, Katolik Reformun sanatını temsil etmiştir. XVII. yüzyılda ülkeler arasında yayılan üslup ortak bir kökene sahip olmasına rağmen coğrafi ve tarihsel farklılıklar nedeniyle uygulandığı ülkelere göre yerel özellik göstermiştir. Barok, Katolik Reform hareketi ile birlikte İtalya toprakları üzerine yayılmıştır. Güney İtalya'nın Puglia bölgesinde yer alan Lecce'de ise Katolik tarikatların etkisi ile birlikte Barok stilde kiliseler inşa edilmeye başlamıştır. Lecce tarihsel süreç içerisinde başta Roma İmparatorluğu olmak üzere Ostrogot, Bizans, Lombard, Norman ve

\footnotetext{
* Bu makale, Dr. Öğr. Üyesi Nadire Tuba YİĞİTPAŞA danışmanlığında yürütülen “Güney İtalya Lecce'de Barok Dönem (XVII. yüzyıl) Kiliseleri / Baroque Period (XVII. century) Churches in Lecce South Italy, Ondokuz Mayıs Üniversitesi, Lisansüstü Eğitim Enstitüsü, Sanat Tarihi Anabilim Dalı, Samsun 2021" künyeli yüksek lisans tezinden üretilmiştir. Literatür taraması ve saha çalışması Ondokuz Mayıs Üniversitesi + Programın'ndan faydalanılarak gerçekleştirilmiş̧tir. Universita del Salento, Universita Degli Studi di Milano ve Sapienza Universita di Roma'nın Kütüphaneleri'nde konu ile ilgili literatür çalışmaları yapılmışırı. Saha çalışması esnasında bilgisini ve desteğini esirgemeyen Universita del Salento Öğretim Üyesi Prof. Dr. Grazia SEMERARO'ya teşekkür ederiz.

** Sanat Tarihçi (MA), İzmir/Türkiye. E-posta: snmcylan92@gmail.com ORCID ID: https://orcid.org/0000$\underline{0001-6487-1196}$

Dr. Öğr. Üyesi, Odokuz Mayıs Üniversitesi, Fen-Edebiyat Fakültesi, Sanat Tarihi Bölümü, Batı Sanatı Anabilim Dalı, Samsun/Türkiye. E-posta: tubayigitpasa @ omu.edu.tr ORCID ID: https://orcid.org/0000-0002-5197-437X
} 
İspanyol hanedanlıklarının yönetimi altında bulunmuştur. Farklı kültürlerden etkilenerek yerel özellikleri ile birlikte bir sentez meydana getirmiştir. Bu sentez, XVII. yüzyıl Barok dönem içerisinde inşa edilen kiliselere de yansımıştır. Lecce'de Barok sanat Roma ve İspanya gibi dış etkenler ile yerel kültürün birleşmesi sonucunda yeni bir stil olarak gelişme göstermiştir. Bölgede tarımsal faaliyetlerin önemli bir yere sahip olmasından dolayı bitkisel bezemeler yerel özellik göstermektedir. İspanyol egemenliği altında bulunmasından kaynaklı olarak "Plateresk ve Churrigueresque" stilini anımsatan yan şapellere sahiptir.

Anahtar Kelimeler: Lecce, Barok, Sanat, Mimari, Heykel, Resim

\begin{abstract}
In the second half of the XVI. century, Baroque, which emerged in Rome in Italy in line with the decisions taken in the Council of Trent, represented the art of the Catholic Reformation. Although the style that spread among countries in the 17th century had a common origin, it showed local characteristics according to the countries where it was applied due to geographical and historical differences. Baroque spread over Italy with the Catholic Reformation movement. In Lecce, located in the Puglia region of Southern Italy, churches in the Baroque style began to be built with the influence of the Catholic sects. Lecce has been under the rule of Ostrogoth, Byzantine, Lombard, Norman and Spanish dynasties, especially the Roman Empire. Influenced by different cultures, it has created a synthesis with its local characteristics. This synthesis, XVII. It is also reflected in the churches built during the 19th century Baroque period. Baroque art in Lecce developed as a new style as a result of the combination of external factors such as Rome and Spain and local culture. Since agricultural activities have an important place in the region, herbal decorations show local characteristics. It has side chapels reminiscent of the "Plateresque and Churrigueresque" style due to its being under Spanish rule.
\end{abstract}

Keywords: Lecce, Baroque, Art, Architecture, Statue, Painting.

\title{
Giriş
}

Lecce tarihsel süreç içerisinde başta Roma İmparatorluğu olmak üzere Ostrogot, Bizans, Lombard, Norman ve İspanyol hanedanlığının yönetimi altında bulunmuştur. Farklı kültürlerden etkilenerek yerel özellikleri ile birlikte bir sentez meydana getirmiştir. Bu sentez XVII. yüzyıl Barok dönem içerisinde inşa edilen kiliselere de yansımıştır. Lecce'de Barok sanat Roma ve İspanya gibi diş etkenler ile yerel kültürün birleşmesi sonucunda yeni bir stil olarak gelişme göstermiştir.

2019 yllında Lecce'de gerçekleştirilen saha çalışmasında Barok dönemi kapsayan XVII. ve XVIII. yüzyıla ait yirmi yedi adet kilise tespit edilmiştir. XVII. yüzyıla ait olan kiliseler, Roma'da Barok stilde inşa edilen kiliseler ile paralel bir gelişme göstermektedir. Fakat XVIII. yüzyıla ait olan kiliseler de Rokoko üslubuna ait bazı özellikler bulunmaktadır. $\mathrm{Bu}$ sebep ile araştırmanın konusu XVII. yüzyılda inşa edilen kiliselerin süslemeleri ile sınırlanmaktadır. Lecce'de XVII. yüzyıla ait olan kiliselerin plan ve mimari özellikleri Kardinal Charles Borromeo (1538-84) ${ }^{1}$ tarafindan belirlenen kurallara uymaktadır. Fakat yerel mimarlar tarafından inşa edilen kiliseler süsleme özellikleri bakımından farklılık göstermektedir.

\section{Barok Sanat}

Barok, Roma Kilisesi'nin Proteston Reform'u karşısında kaybettiği otoriteyi ve itibarı geri kazanmak için başlatmış olduğu Karşı Reform ya da Katolik Reformun sanatı olarak gelişme göstermiş̧ir. Martin Luther, azizlere olan saygıyı reddetmiş ve Kalvinistler ise

\footnotetext{
${ }^{1} 1577$ yılında kendisini kilisenin reformuna adamış olan Kardinal Charles Borromeo "Kiliseler için İnşa ve Dekorasyon Talimatları" adlı bir tez yayımlamıştır. Bkz: Neuman 2013, 125; Minor 1999, 77-78; Evelyn 1977, 50-60.
} 
Katolik kiliselerinde yer alan görsel imgelerin kötüye kullanıldığını savunmuştur. ${ }^{2}$ Ayrıca Martin Luther, Hristiyanların kurtuluşu için iyi eserlere ihtiyacı olmadığını en önemlisinin inanç ile kutsal kitap olduğunu vurgulamıştır. 1545-1563 yılları arasında gerçekleştirilmiş olan Trent Konsili'nde bu düşüncelere karşı çıkılarak müzik, resim, heykel ve mimarinin dini bağlılı̆̆ı arttıran en güçlü araçlar arasında yer aldığı kararına varılmıştır. ${ }^{3}$ Ayrıca konsilde, ibadet için mistik bir atmosfer yaratılması adına resim ve heykel tasvirlerinin yoğun bir şekilde kullanımına teşvik edilmiştir. Böylece Barok, Trent Konsili'nde alınan kararlar doğrultusunda ortaya çıkmıştır. Cizvit Tarikatı ise Hristiyanlık öğretisinin yayılması ve Barok sanatının gelişmesinde büyük bir rol oynamıştır. ${ }^{4}$

XVI ile XVII. yüzyılda Avrupa toprakları üzerinde yaşanan ekonomik ve siyasi faktörler de Barok sanatının gelişmesinde etkili olmuştur. ${ }^{5}$ XVII. yüzyılın ilk yarısında Katolikler ve Protestanlar arasında gerçekleşen "Otuz Yıl Savaşları (1618-1648)" sonucunda sosyal krizler yaşanmıştır. ${ }^{6}$ Yaşanan bu gelişmeler neticesinde burjuva sınıfı eski siyasal ve ekonomik gücünü yitirmeye başlamıştır. Böylece XVII. yüzyılda, iktidar gücünü Tanrı'dan aldıklarına inanan krallar, mutlak monarşi yönetimi sayesinde devletin bütün gücünü elinde toplayarak sanatın gelişmesinde rol oynamıştır. ${ }^{7}$

İtalya/Roma'da ortaya çıkmış olan Barok sanat, Karşı Reform hareketinin etkisi altında bulunan Fransa, İspanya, Belçika (Flandre), Almanya, Avusturya ve Latin Amerika gibi Katolik ülkelere yayılmıştır. ${ }^{8}$ Kuzey Almanya, Hollanda ve İngiltere gibi Protestan ülkelerde de uygulama alanı bulmuştur. ${ }^{9}$ Barok sanat ortak bir kökene sahip olmasına rağmen coğrafi ve tarihsel farklılıklar nedeniyle uygulandığı ülkelere göre yerel özellikler göstermiştir. Fakat ülkelere göre farklı tutumlar sergilemesine rağmen boyutlarından bağımsız olarak coşku, bolluk ve dramatik etki değişmeyen özelliklerini temsil etmiştir. Ayrıca İtalyan Barok sanatı bazı eleştirmenler tarafindan Erken (1585-1625), Yüksek (1625-1675) ve Geç (1675-1715) olmak üzere üç döneme ayrılmaktadır. ${ }^{10}$

Barok döneminde kilise tasarımlarında estetikten ziyade işlevsellik ön plana çıkmıştır. $\mathrm{Bu}$ durum reforme edilmiş olan Katolik Kilisesi içerisindeki yeni ayin ve adanmışlık kurallarından dolayı kaynaklanmaktadır. Karşı Reform sürecinde dini yapılar; ayin, günah çıkarma, dua ve vaaz gibi çeşitli liturjik işlevlere uygun olarak tasarlanmıştır. Barok döneminde, kilise içerisinde yer alan günah çıkarma standı bir tür özel dini mobilya haline dönüşmüştür. Ayrıca XVII. yüzyılda vaazların konuları, kilisenin ihtişamı üzerine genişletilerek iç mekânlarda görkemli vizyonları gerekli kılmıştır. ${ }^{11}$ "Kiliseler için İnşa ve Dekorasyon Talimatları" isimli tezde ise İsa'nın çarmıha gerilmesi, Meryem ile azizler gibi belirli Katolik öğretilerinin sunak panosu ve resimlerde tasvir edilmesi belirtilmiştir. Böylece resim ve heykel gibi zengin süslemelere sahip tiyatrovari dekorasyonların yardımıyla ibadet edenlere daha güçlü bir maneviyat duygusu kazandırmak amaçlanmıştır.

\footnotetext{
${ }^{2}$ Hibbard 1977, 110-111.

${ }^{3}$ Held-Poster 1971, 22.

${ }^{4}$ Cook 1972, 169.

${ }^{5}$ Minor 1999, 41-42.

${ }^{6}$ Adams 2011,

${ }^{7}$ Millon 1968, 9.

${ }^{8}$ Glancey 2003, 82.

${ }^{9}$ Held-Poster 1971, 84.

${ }^{10}$ Germaner 1997, 195.

${ }^{11}$ Minor 1999, 78.
} 


\section{Lecce'de Barok Sanat}

Trent Konsili'nin ardından gelişme gösteren Karşı Reform hareketi ile birlikte Barok sanat İtalya toprakları üzerine yayılmıştır. ${ }^{12}$ Napoli Krallığına bağlı bulunan Lecce, Barok stilde yeniden inşa edilmeye başlamıştır. ${ }^{13}$ Lecce'de Barok sanatın ortaya çıkma nedenlerinden bir diğeri Osmanlı Devleti'nin 1571 yılında İnebahtı'da yenilgiye uğratılması olmuştur. Osmanlı Devleti tarafından gerçekleştirilecek bir saldırı tehdidinin ortadan kalkmasıyla birlikte kent soyluları şehir ve saray yaşantısından zevk almaya yönelmiştir. Yaşanan bütün bu gelişmelerin sonucunda XVII. yüzy1lda Piskopos Luigi Pappacoda (16391670) başta olmak üzere kent soyluların destekleriyle birlikte Barok tarzda kilise ve saraylar inşa edilmiştir. ${ }^{14}$ Fakat Roma ve İspanya gibi dış etkenler ile yerel kültürün birleştirilmesi sonucunda yeni bir stil olarak gelişme göstermiştir. 1606 y1lında Mimar Francesco Antonio Zimbalo (1567-1630) tarafından tasarlanan Santa Croce Kilisesi'nin batı cephesindeki üç adet portal ise Barok sanatın başlangıcını temsil etmiştir. ${ }^{15}$ Ayrıca Antonio Zimbalo dini ikonografik geleneğe uygun olarak mekânların dikeyliğini vurgulayan formlar oluşturmuştur.

Lecce'de Barok, mimar Giuseppe Zimbalo (1620-1710) ve Giuseppe Cino (16451722) tarafından gelişme göstermiştir. Giuseppe Zimbalo zengin dekoratif mimari düzelemeleri sayesinde Barok stilini olgunluk aşamasına yükseltmiştir. Aynı zamanda heykeltıraş da olan Zimbalo, Piskopos Luigi Pappacoda'nın isteği doğrultusunda pek çok dini ve sivil yapı inşa etmiştir. Böylece Mimar Zimbalo'nın çalışmaları ve ünü sadece Lecce ile sınırlı kalmayarak bütün eyalete yayılmıştır.

Kiliselerin cepheleri yumuşak ve kolay işlenebilen Lecce taşının yardımıyla zengin dekoratif ögelerle bezenmiştir. ${ }^{16}$ Salento bölgesine özgü olan Lecce taşı işlenebilir ve dayanıklı olması ile dikkat çekmiştir. Günümüzde de kullanılmaya devam edilen bu taş toprağın altından çıkarıldığında beyaz renge sahip olmasına rağmen güneşin etkisiyle birlikte sarı veya grimsi bir siyah renk tonuna dönüşmektedir. Lecce taşı özellikle tonozların itme kuvveti ve binalardaki azalan yüksekliği dışa yansıtmamak için teknik bilgilerden yoksun olan yerel usta ve mimarlar tarafindan kullanılmıştır. Sanatçılar tarafından ise sütun, başlık, kaide, korniş, friz, alınlık, heykel gibi mimari öge ve bezemelerde en ince ayrıntıya kadar kolay işlenebilmesinden dolayı tercih edilmiştir.

Lecce'de Barok sanatının en karakteristik özelliğini kiliselerin cephelerinde yer alan zengin mimari plastik süslemeler temsil etmektedir. Pitoresk dekorasyonlara sahip olan kiliseler Roma' da tasarlanan Barok kiliselerin süslemelerinden farklılık göstermektedir. Bitkisel süslemeleriyle dikkat çeken iç ve dış cephelerde yoğun bir şekilde çiçek, yaprak, meyve gibi kompozisyonlara yer verilmiştir. Kiliselerin iç ve diş dekorasyonunda yer alan korint sütun başlığı ayırt edici bir unsur olarak akantus yapraklarına benzer birçok farklı bitki yapraklarıyla bezenmektedir. Dini sahnelerin yanı sıra mitolojik figürlerin de betimlenmiş olduğu kiliselerin cephe ve iç mekânlarında solomon olarak adlandırılan sarmal sütunlar yer almaktadır. Bununla birlikte kilise cephelerinde fantastik karakterler, melek ve aziz figürlerinin tasvirleri mevcuttur. Özellikle dış cephelerde insan ve hayvan formuna sahip telamonlar dikkat çekmektedir. XVII. ve XVIII. yüzyıl arasında cartapesta tekniği ön plana çıkmıştır. ${ }^{17}$ Alçı, kâğıt, saman, macun, boya ve su malzemelerinden elde edilen bu teknik sayesinde kiliselerin iç mekânları polikrom heykeller ile donatılmıştır.

\footnotetext{
${ }^{12}$ Pijoan 1940, 237; Galante 2006, 25.

${ }^{13}$ Raho vd. 2019, 3.

${ }^{14}$ Paone $1979,12$.

${ }^{15}$ Sitwell 1967, 6.

${ }_{16}$ Marcelli 2015, 151.

${ }^{17}$ Roiss 2006, 115-117.
} 


\section{Lecce'de XVII. Yüzyıl Barok Dönem Kilise Planları}

XVII. yüzyılda Lecce'de Barok döneme ait toplam on üç adet kilise inşa edilmiştir. Bunlar; Basilica di Santa Croce (Kutsal Haç Bazilikası), Chiesa di S. Maria dell'Idria (Kutsal Meryem dell'Idria Kilisesi), Chiesa di Santa Teresa (Azize Teresa Kilisesi), Chiesa La Madre di Dio e S. Nicola (Tanrı'nın Annesi ve Aziz Nicola Kilisesi), Chiesa S. Maria di Ognibene (Ognibene Kutsal Meryem Kilisesi), Duomo di Lecce (Lecce Katedrali), Chiesa di Sant'Angeo o di Santa Maria di Costantinopoli (Aziz Angelo ya da İstanbul'un Kutsal Meryem'i Kilisesi), Chiesa di San Matteo (Aziz Matta Kilisesi), Chiesa di San Giacomo (Aziz Giacomo Kilisesi), Chiesa di Sant'Anna (Azize Anna Kilisesi), Chiesa di Santa Chiara (Azize Chiara Kilisesi), Chiesa di San Giovanni Battista (Aziz Vaftizci Yahya Kilisesi), Chiesa di San Francesco d'Assisi (Aziz Francesco d'Assisi Kilisesi)'dir.

XVII. yüzyılda Lecce'de Celestin, Fransisken, Carmelitani Scalzi, Augustin, Alcantarini ve Piskopos Luigi Pappacoda önderliğinde yeni kiliseler inşa edilmiştir. Bu yapılar yerel mimar ve ustalar tarafından tasarlanmıştır. Kiliselerin plan ve mimari özellikleri bakımından Roma Barok modeller ile "Kiliseler için İnşa ve Dekorasyon Talimatları" isimli tezde belirlenmiş olan özelliklere uymakta olduğu saptanmıştır. Ayrıca bu kiliselerin planları beş gruba ayrılmaktadır. Bunlar ise Latin haçı, Yunan haçı, dikdörtgen, eliptik ve sekizgen planlı olarak gruplandırılmaktadır. Latin haçı planına sahip olan kiliseler ise tek ve üç nefli olarak düzenleme göstermektedir.

Basilica di Santa Croce (Kutsal Haç Bazilikası), Duomo di Lecce (Lecce Katedrali), Chiesa di Santa Teresa (Azize Teresa Kilisesi), Chiesa di Sant'Angeo o di Santa Maria di Costantinopoli (Aziz Angelo ya da İstanbul'un Kutsal Meryem'i Kilisesi), Chiesa di S. Maria dell'Idria (Kutsal Meryem dell'Idria Kilisesi), Chiesa S. Maria di Ognibene (Ognibene Kutsal Meryem Kilisesi) ve Chiesa di San Giacomo (Aziz Giacomo Kilisesi) Latin haçı plana sahiptir. Chiesa di San Giovanni Battista (Aziz Vaftizci Yahya Kilisesi) ve Chiesa di San Francesco d'Assisi (Aziz Francesco d'Assisi Kilisesi) ise Yunan haçı planındadır. Bu doğrultuda yukarıda yer alan kiliselerin planları "Kiliseler için İşsa ve Dekorasyon Talimatlart" isimli teze uygun olarak planlanmıştır.

Chiesa di Santa Teresa (Azize Teresa Kilisesi), Chiesa di Sant'Angeo o di Santa Maria di Costantinopoli (Aziz Angelo ya da İstanbul'un Kutsal Meryem'i Kilisesi), Chiesa di S. Maria dell'Idria (Kutsal Meryem dell'Idria Kilisesi), Chiesa S. Maria di Ognibene (Ognibene Kutsal Meryem Kilisesi) ve Chiesa di San Giacomo (Aziz Giacomo Kilisesi)' nin planları ise Roma'da Barok mimarinin en erken örneği temsil eden Il Gesu Kilisesi'nin planı ile benzerlik göstermektedir.

Roma'da "Yüksek Barok" olarak adlandırılan dönem içerisinde kilise planları değişiklik göstermeye başlamıştır. ${ }^{18}$ Geometrik şekillerden türemiş olan tasarımlar ile elips ve oval planlar ön plana çıkmıştır. Yapılan araştırmalar sonucunda bu planların, kiliselerin konumlandırıldığı alan ve aristokrat ya da din görevlilerin istekleri doğrultusunda küçük yan şapellerin eklenmesinden dolayı ön plana çıktığı düşünülmektedir. Roma'da Yüksek Barok döneminde Francesco Borromini tarafindan inşa edilen San Carlo alle Quattro Fontane Kilisesi'nin planı, Lecce'de Achille Larducci tarafindan tasarlanan Chiesa di San Matteo (Aziz Matta Kilisesi) ve Giuseppe Cino tarafindan tamamlanan Chiesa di Santa Chiara (Azize Chiara Kilisesi)'nin planına örnek teşkil etmektedir.

\footnotetext{
${ }^{18}$ Held-Poster 1971, 31-32.
} 


\section{Lecce'de XVII. Yüzyıl Barok Dönem Kilise Süslemeleri}

Lecce'ye özgü olarak kiliselerin batı cephelerindeki sütun ve pilastr başlıkları akantus yapraklarına benzer birçok farklı bitki yaprakları ile kaplıdır. Bu yapraklar putto büstü, aslan, grifon, fantastik hayvan, telamon, karyatid, geometrik ve meyve salkımları gibi motifler ile çevrelenmektedir. Basilica di Santa Croce (Res. 1, 2), Chiesa La Madre di Dio e S. Nicola, Chiesa S. Maria di Ognibene, Duomo di Lecce (Res. 3), Chiesa di Sant'Angeo o di Santa Maria di Costantinopoli ve Chiesa di San Giovanni Battista bu forma uygun düzenleme göstermektedir.

Chiesa di San Matteo'nun batı cephesindeki yer alan portal ve niş, İspanya'da Barok dönemde ortaya çıkan "Churrigueresque"19 stilinin vazgeçilmez mimari ögesi olan estipite sütununa sahiptir (Res. 4, 5).

Basilica di Santa Croce, Duomo di Lecce (Res.6), Chiesa di Sant'Angeo o di Santa Maria di Costantinopoli (Res. 7), Chiesa di San Matteo (Res. 4), Chiesa di Santa Chiara (Res. 8) ve Chiesa di San Giovanni Battista'nın portali zengin bir şekilde dekore edilmesi ile Plateresk ${ }^{20}$ ve Churrigueresgue" stilinde tasarlanan portalleri anımsatmaktadır (Res. 9, 10).

Lecce'de XVII. yüzyıl Barok dönem içeresinde inşa edilen kiliselerin iç mekânları küçük yan şapeller ile çevrelenmektedir. Basilica di Santa Croce ve Duomo di Lecce'nin iç mekânında şapeller yan nefte yer almaktadır. Diğer kiliselerde ise nefin kuzey ve güney duvarında sıralanmaktadır. Bu şapellere birkaç basamaklı merdiven ile ulaşılmakta olup önlerine sunak masası yerleştirilmiştir. Eksenlerinde sütun ve pilastr ile sınırlanan yağlı boya tablo ya da heykel figürleri bulunmaktadır.

Basilica di Santa Croce "Aziz Francesco di Paola (Res. 11)”, Duomo di Lecce "Aziz Antonio da Padova (Res. 12), Meryem'in Günahsız Gebeliği (Res. 13)”, Aziz Filippo Neri (Res. 14)" ve Haç (Res. 15)", Chiesa di Sant'Angeo o di Santa Maria di Costantinopoli "Üzgün Meryem (Res. 16)" şapeli Plateresk ve Churrigueresgue stilinde tasarlanan şapelleri anımsatmakta olup izleyicinin dikkatini çekmektedir (Res. 17, 18).

Lecce'de, XVII. yüzyılda Barok dönem içerisinde inşa edilen kiliseler bitkisel, geometrik ve figürlü bezemeler ile kaplıdır. Volüt, vazodan çıkan çiçek, akantus yaprağı, meyve salkımı, gül bezek, nar çiçeği, girland, yaprak ve yaprak dalı ile mızrak uçlu bitkisel bezeme çok sik tercih edilen motifleri içermektedir. Tondo çerçeve, madalyon, dilimli silindirik süsleme, perde, taç, istiridye, dentil, arma ve kartuşlar gibi motifler de yoğun olarak kullanılmıştır. Ayrıca sfenks, putto büstü, havari büstü, aslan, kartal, kuş, fantastik canavar ve insan büstü gibi figürlü bezemeler de betimlenmiştir. Kiliselerin batı cepheleri ve iç

\footnotetext{
${ }^{19}$ İspanya'da XVII ve XVIII. yüzyılda, Mudejar üslubu ve Amerika sanatının yerel dekoratif geleneğinin etkileri ile birlikte "Churrigueresque" stili ortaya çıkmıştır. Plateresk stilinden etkilenerek gelişme göstermiştir. Adını İspanyol mimarlardan oluşan Churriguera ailesinin soy isminden almıştır. Churrigueresque stilinde, özellikle kiliselerin cephe ve şapelleri oldukça zengin bir şekilde dekore edilmiştir. Mimaride yüzey, kırık alınlık, dalgalı korniş, ters kıvrım, kalın pervaz ve korkuluklara yansımıştır. Solomon olarak adlandırılan sarmal sütunlar, geometrik paneller, melek, putto ve alçak kabartma heykelleri ile ters çevrilmiş bir koni ya da dikilitaş şekline sahip estipite sütunları en yaygın motifler arasında yer almaktadır. İç mekânlarda altı yaldız kullanımı ağır basmıştır. Ayrıca İspanya'nın sömürgesi olan Latin Amerika da Churrigueresque stilinin etkisi altında kalmıştır. Bkz: Held-Posner 1971, 194; Kelemen 1967, 180-190.

${ }^{20}$ İspanya'da, XVI. yüzyıl boyunca "Plateresk" olarak adlandırılan stil gelişme göstermiştir. Bu stil Geç gotik, Rönesans ve Mudejar üslubunun birleşiminden meydana gelmektedir. Mimari süsleme tarzı olarak ortaya çıkmıştır. Yapıların portal, pencere, niş ve şapelleri zengin süsleme unsurları ile dikkat çekmektedir. Bitkisel bezeme ise en karakteristik özelliğini yansıtmaktadır. Pencerelerin alt bölümlerinde, duvar yüzeylerinde ve pilastrlerin arasında madalyon motifi çok sık tercih edilmektedir. Alınlık ve tepelik bölümlerinde vazodan çıkan çiçek motifleri kullanılmıştır. Bunun yanı sıra hanedan armaları, girland, hayvan figürleri ve altın yaldızlı paneller yoğun olarak kullanılan süsleme unsurlarıdır. Bkz: Vey-Salas 1966, 293.
} 
mekânlarında, yukarıda bahsedilen bezemeler bir bütün halinde yoğun olarak görülmektedir. Sütun, pilastr, pulvino, kemer, portal, pencere, niş, friz, alınlık, çerçeve, bordür, tavan, kaide ve şapeller; bitkisel, geometrik, sembolik ve figürlü bezemeler ile hareketlilik kazanmaktadır.

Kiliselerin batı cephe ve iç mekânlarında tek veya çok figürlü heykel tasvirleri bulunmaktadır. Batı cephelerde yer alan heykel figürleri genellikle niş, portal, korkuluk, friz, volüt ve alınlıklarda görülmektedir. İç mekânlarda ise şapellerde yer almaktadır. Şapellerin sunak masası, niş ve tepelik bölümlerinde heykel figürleri sıralanmaktadır.

Yapılarda, "Kiliseler için İnşa ve Dekorasyon Talimatları" isimli teze göre İsa peygamber, İsa'nın çarmıha gerilmesi, Meryem, Meryem ve çocuk İsa figürleri başta olmak üzere kanonik İncil yazarları, havariler, Kitab-1 Mukaddes'te adı geçen bireyler, aziz ve azizeler, papalar, tarikat kurucuları, melek ve putto gibi tek figürlü heykellere rastlanmaktadır.

Karşı Reform hareketinin sanatı olan Barok, Cizvit tarikatının vaaza vermiş olduğu önemden dolayı görkemli vizyonları gerekli kılmıştır. Bu doğrultuda Lecce'de XVII. yüzyılda inşa edilen heykel figürleri 1şık ve gölge kontrastları ile tiyatrovari bir şekilde betimlenmiştir. Hareket hissi uyandırmak amacıyla figürler Yunan heykel sanatının klasik döneminde ortaya çıkan "S" kıvrımı ile tasvir edilmiştir. Ağırlık yükü taşıyıcı bacak üstüne verilerek serbest olan diğer bacak ile figürlerde esneklik ve hareketlilik sağlanmaktadır. Heykel figürlerinin vücut ve yüz ifadelerindeki duygu gerçekçi bir anlatım ile yansıtılmıştır. İzleyicide dikeylik hissi uyandırmak amacıyla elbise kıvrımları paralel çizgiler ile oyulmuştur. Ayrıca Lecce'ye özgü olarak kiliselerin iç mekânlarında cartapesta tekniğinde polikrom tek figürlü heykeller betimlenmiştir.

Kiliselerin iç mekânları ise yağlı boya tablo, vitray ve freskler ile süslenmiştir. Yağglı boya tablolar genel olarak şapel, tepelik, tavan ve presbyterium bölümlerinde görülmektedir. Şapellerde tablolar sütunlar ile çevrili olan eksende yer almaktadır. Ayrıca yine şapellerin tepelik bölümlerinde geometrik çerçeveler içerisinde bulunmaktadır. Kiliselerin düz tavanları çerçeveler içerisinde yer alan yağlı boya tabloları ile dikkat çekmektedir. Presbyterium bölümlerinde ise çerçeveler içerisinde kuzey, güney ve doğu duvarlarına asılı vaziyettedir.

Bu tablolar "Kiliseler için İnşa ve Dekorasyon Talimatları" isimli teze göre İsa'nın çarmıha gerilmesi, Meryem, azizler, azizeler, havariler ve Kitab-1 Mukaddes'te geçen belirli Katolik öğretilerini konu almaktadır.

Dini konuları içeren sahnelerde figürlere; atmosfer yoğunluğu, derinlik, renk, 1şık ve gölge zıtlıkları ile hareketlilik yansıtılmaktadır. Sanatçılar anın ya da bir olayın sahnelenmiş olduğu kompozisyoları 1şık ve gölge zıtlıkları sayesinde gerçeklik duygusunu dolaysız bir şekilde yansıtmaktadır. Gölge ve 1şık zıtlıklarıyla meydana gelen dramatik etki ise tiyatral bir şekilde izleyiciyi kompozisyona çekmektedir. Doğalcı bir anlayış ile tasvir edilen tablolarda genel olarak zıtlık oluşturan açık ve koyu renkler tercih edilmiştir. Ayrıca sahnenin gölgeli alanları tek bir noktadan gelen 1şı̆̆ın düşmesi ile aydınlatılmaktadır.

Vitray ise aydınlık katı, transept ve apsis bölümleri olmak üzere iç mekânlarda yer alan pencerelerde görülmektedir. Bu pencerelerde İsa, Meryem, aziz ya da azize gibi dini figürlerin yanı sıra Kitab-1 Mukaddes'te yer alan konuların sahnelenmiştir. Ayrıca pencereler vitray tekniği ile bitkisel ve geometrik bezemeleri içeren kompozisyonlar ile boyalıdır.

Barok dönem içerisinde kubbelerin fresk tekniği ile boyanması en karakteristik özellikleri arasındadır. Ziyaretçide kiliselerin tavanları gökyüzüne doğru uzanıyor hissi yaratılarak tiyatral ve hareketli formlara sahip figürler ile bezenmiştir. Lecce'de ise fresk tekniği Duomo di Lecce'de uygulanmıştır. Duomo di Lecce'de yer alan "Haç" isimli şapelin kuzey ve güney duvarı ile kubbesi fresk tekniği ile boyalıdır (Res. 19). Kuzey duvarında "Golgota Yolunda İsa", güney duvarında "İsa'nın Çarmıha Gerilmesi” ve kubbesinde ise 
İsa'nın çilesine atıfta bulunarak eşyalarını taşımakta olan putto ile melek figürleri resimlenmiştir. Katedralin kubbesinde betimlenen figürler, perspektif açısından yukarıya doğru küçülerek yerleştirilmiştir.

\section{Değerlendirme ve Sonuç}

Barok sanat ortak bir kökene sahip olmasına rağmen uygulandığı ülkelere göre coğrafi, tarihsel ve ekonomik faktörlerin etkisi ile beraber yerel özellikler göstermiştir. Ülkelere göre farklı tutumlar sergilemesine rağmen coşku, bolluk ve dramatik etki değişmeyen özellikleri arasında yer almaktadır.

Güney İtalya'nın Puglia bölgesinde bulunan Lecce coğrafi konumu itibari ile tarihsel süreç içerisinde farklı kültürlerin etkisi altında kalmıştır. Farklı kültürlerden etkilenerek yerel özellikleri ile birlikte bir sentez meydana getirmiştir. Bunun sonucunda Lecce'de Barok sanat yeni bir stil olarak gelişme göstermiştir.

Barok sanatın temeli Kardinal Charles Borromeo tarafından kaleme alınan "Kiliseler için İnşa ve Dekorasyon Talimatları" isimli teze dayanmaktadır. Cizvit tarikatı ise Borromeo tarafından belirlenen kurallara göre kiliseler inşa edilmesine öncülük etmiştir.

Lecce'deki kilise süslemeleri, Roma'da bulunan Barok süslemelerinden farklılık göstermektedir. Kiliseler kolay işlenebilen Lecce taşı ile inşa edilmelerinden dolayı yoğun süslemelere sahiptirler. Batı cepheleri ve iç mekânları zengin dekoratif ögelerle bezelidir.

Kiliseye gelen ziyaretçi ilk olarak giriş cephesi olan batı cepheyi görmektedir. $\mathrm{Bu}$ sebep ile kiliselerin batı cephelerinde yoğun süslemeler bulunmaktadır. Duomo di Lecce kilisesi ise en güzel örneği temsil etmektedir. Katedralin, Duomo Meydanı'nda yer almasından dolayı ziyaretçi ilk olarak kuzey cepheyi görmektedir. $\mathrm{Bu}$ nedenle kuzey cephesinde süslemeye yer verilmiştir.

Kiliseler "Eski Şehir" olarak adlandırılan merkezde yer almaktadırlar. Bu merkez dar sokaklara ve birbirine bitişik yapılara sahiptir. Genel olarak kiliselerin kuzey, güney ve doğu cephelerinde bitişik olarak manastır ya da bireye özel binalar bulunmaktadır. Bitişik olarak binaların yer almasından ve giriş cephesini temsil etmemelerinden dolayı herhangi bir üslup özellikleri bulunmamaktadır. Manastır binaları kiliseler ile yakın tarihlerde inşa edilmiştir. Fakat özel konutların hangi tarihlerde inşa süreçlerinin başladığına dair bilgiye ulaşılamamıştır.

Lecce'de Barok sanatının en karakteristik özelliğini, kiliselerin batı cephelerinde yer alan zengin mimari plastik süslemeler temsil etmektedir. Kiliselerin batı cephelerindeki sütunlar, pilastrler, portaller, pencereler, niş, friz ve alınlıklar yoğun süslemeleri ile dikkat çekmektedir. Bu mimari ögeler bitkisel, geometrik, sembolik, figürlü bezeme ve heykeller ile donatılmıştır.

İç mekânlarda süsleme ise küçük yan şapeller, presbyterium bölümleri ve tavanlarında görülmektedir. Özellikle yan şapeller yoğun süslemere sahiptir. Solomon ve karyatid sütunlar, kuş ve aslan gibi hayvan figürleri, melek, putto, madalyon, bitkisel bezemeler, yağlı boya tablolar ve heykeller ile şapeller dikkat çekmektedir.

Batı cephe ve iç mekânlarda görülen bu süslemeler, İspanya gibi dış etkenler ile yerel kültürün birleşmesi sonucunda gelişme göstermiştir. XV. yüzyılda İspanya egemenliği altına giren Lecce, hem İspanyol kültüründen etkilenmiş hemde kendi kültürünü İspanya'ya tanıtmıştır. Bu ise XVII. yüzyılda inşa edilen kiliselerin süslemelerine yansımıştır. 
İspanya'da XVI. yüzyıla egemen olan "Plateresk" ve XVII. ile XVIII. yüzyılda görülen "Churrigueresque" stili, Lecce'deki kiliselerin süslemelerini anımsatmaktadır. ${ }^{21}$

Kiliselerin portal, pencere, niş, alınlık ve tepelik bölümleri bitkisel bezemenin yoğunlukta olduğu süslemeler ile hareketlilik kazanmaktadır. Madalyon motifi, hayvan figürleri, vazodan çıkan çiçek motifleri, hanedan armaları, girland ve altın yaldızlı çerçeveler Plateresk stilini anımsatmaktadır.

San Matteo Kilisesi'nin batı cephesindeki portal ve nişi çevreleyen estipite sütunları ile Duomo di Lecce'de iç mekânda yer alan ambonun estipite sütunları, Churrigueresque stilinin karakteristik özelliğidir.

İç mekânlarda yer alan yan şapeller, zengin dekoratif süslemeleri ile İspanya'da Churriguereque stilinde tasarlanan şapeller ile benzerlik göstermektedir. Ayrıca şapellerde kullanılan solomon sütunları, Churrigueresque stilinin yanı sira Roma'da San Pietro Bazilikası'nın iç mekânında Gian Lorenzo Bernini tarafından tasarlanan baldaken için de kullanılmıştır.

Heykel ve yağlı boya resimlerinin konuları "Kiliseler için İnşa ve Dekorasyon Talimatları" isimli teze göre seçilmiştir. Bunlar ise İsa'nın çarmıha gerilmesi, Meryem, azizler ve Kitab-1 Mukaddes'te ismi geçen önemli şahışlar ya da olaylar gibi Katolik öğretilerini içeren sahnelerdir.

Ekonomik etkenlerden dolayı kiliselerin iç mekânlarında cartapesta tekniğinde tasarlanan polikrom heykeller, Lecce Barok sanatının en karakteristik özelliğini yansitmaktadir.

Lecce’ye özgü olarak korint sütun başlığı, akantus yapraklarına benzer birçok farklı bitki yapraklarıyla süslenmiştir. Bunun yanı sıra iç mekânlarda karyatid ve alışılmışın dışında tasarlanmış olan bitkisel bezemelerle kaplı sütunlar da bulunmaktadır.

Lecce kiliselerinde yerel özellik olarak pencereler, nefin çevre duvarlarında yer alan kornişin üzerine hafif çıkıntılı şekilde yerleştirilerek iç mekânlarda loş bir hava sağlamaktadır. Böylece iç dekorasyonda, ışık ve gölge kontrastlarının yardımıyla en küçük ayrıntılar bile algilanmaktadir.

\section{Kaynakça}

Adams, Scheider, Laurie, 2011, A History of Western Art, NewYork, McGraw-Hill.

Cazzato, V.-Cazzato, M. 2015, Lecce il Salento i Centri Urbani le Architetture e il Cantiere Barocco I, Roma, De Luca Editori D’Arte.

Cook, Frere, Gervis, 1972, Art and Arthitecture of Christianity, Cleveland, The Press of Case Western Reverse University.

Evelyn, Carole, V. 1977, Charles Borromeo's Instructiones Fabricae et Supellectilis Ecclesiasticae, 1577: A Translation with Commentary and Analysis, NewYork, Syracues University.

\footnotetext{
${ }^{21}$ Bazı kaynaklarda bu süslemelerin Osmanlı Sanatı etisinde tasarlanıldığına değinilmektedir. Bknz; Üntak Tarhan, 2020, 24.
} 
Galante, S. 2006, Materia, Forma e Tecniche costruttive in Terra d'Otranto, Da Esperienza Locale a Metodologia per la Conservazione, Universita Degli Studi di Napoli "Federico II" Facolta' d'Architettura, (Yayımlanmamış Doktora Tezi), Napoli.

Germaner, Semra, 1997, "Barok Üslup”, Eczacıbaşı Sanat Ansiklopedisi, İstanbul, Yem Yayın, 1, 194-197.

Glancey, Jonathan, 2003, The Story of Architecture, New York, Dorling Kindersley.

Held, J.-Posner, D. 1971, 17th and 18th Century Art Baroque Painting Sculpture Architecture, New York, Harry N. Abrams.

Hibbard, Howard, 1997, Masterpieces of Western Sculpture from Medieval from Medieval to Modern, New York, Harper\&Row Publishers.

Kelemen, P. 1967, Baroque and Rococo in Latin America, New York, Dover Publications Inc.

Marcelli, A. 2015, “Lecce, Perla Barocca”, Master Meeting Italy's Best International, 21, 150-156.

Millon, A. H., 1968, Baroque \& Rococo Architecture, London, Studio Vista.

Minor, Hyde, V. 1999, Baroque \& Rokoko Art \& Culture, New Jersey, Prentice Hall.

Minor, Hyde, Vernon, 1999, Baroque \& Rokoko Art \& Culture, New Jersey, Prentice Hall.

Neuman, R. 2013, Baroque and Rococo Art and Architecture, New Jersey, Pearson.

Paone, M. 1979, Lecce Elegia del Barocco, Lecce, Congedo Editore.

Paone, M. 1979, Chiese di Lecce II, Lecce, Congedo Editore.

Paone, M. 1981, Chiese di Lecce I, Lecce, Congedo Editore.

Pijoan, J. 1940, Art in the Modern World European Renaissance Baroque Modern Art, Chicago, University of Knowledge Incorporated.

Raho, E. 2019, "Ipotesi Sulla Presenza di Glaucium Flavum nel Barocco Leccese”, Natiziario della Societa Botanica Italiana, 3, 1-3.

Roiss, Rossi, E. 2006, Cartapesteide. Urbino, Edizioni Quattro Venti.

Sitwell, S. 1967, Baroque and Rococo, New York, G. P. Putnam's Sons.

Tarhan, Üntak, A. 2020, "Kültürel Karşılaşmalar: İtalya'daki Lecce Kentinin Barok Mimarisi Üzerindeki Olası Osmanlı Sanatı Etkileri”, Sanat Tarihi Yıllı̆̆l, 29, 201-246.

Vey, H.-Salas, de, X. 1966, German and Spanish Art to 1900, New York, Grolier Incorporated.

\section{Görsel Kaynakça}

Şek. 25. Caravaca de La Cruz Bazilikası, Estipite Sütun, https://en.wikipedia.org/wiki/File:Caravaca_de_la_Cruz_castle_column.JPG, (Erişim Tarihi: 27.05.2021).

Şek. 31. La Compania de Jesus Kilisesi, Portal, https://en.wikipedia.org/wiki/Church_of_la_Compa\%C3\%B1\%C3\%ADa_de_Jes\%C 3\%BAs,_Quito, (Erişim Tarihi: 27. 05. 2021).

Şek. 32. MurciaKatedral, Portal, https://en.wikipedia.org/wiki/Murcia_Cathedral\#/media/File:Murcia_Catedral1_tango 7174.jpg, (Erişim Tarihi: 27. 05. 2021). 
Şek. 43. San Esteban Şapel, https://es.wikipedia.org/wiki/Convento_de_San_Esteban_(Salamanca), (Erişim Tarihi: 28.05.2021).

Şek. 44. San Cosme y San Damian de Arnedo, Şapel, https://www.birigay.es/?portfolio=retablo-mayor-de-san-cosme-y-san-damian-dearnedo, (Erişim Tarihi: 28. 05. 2021).

\section{FOTOĞRAFLAR}

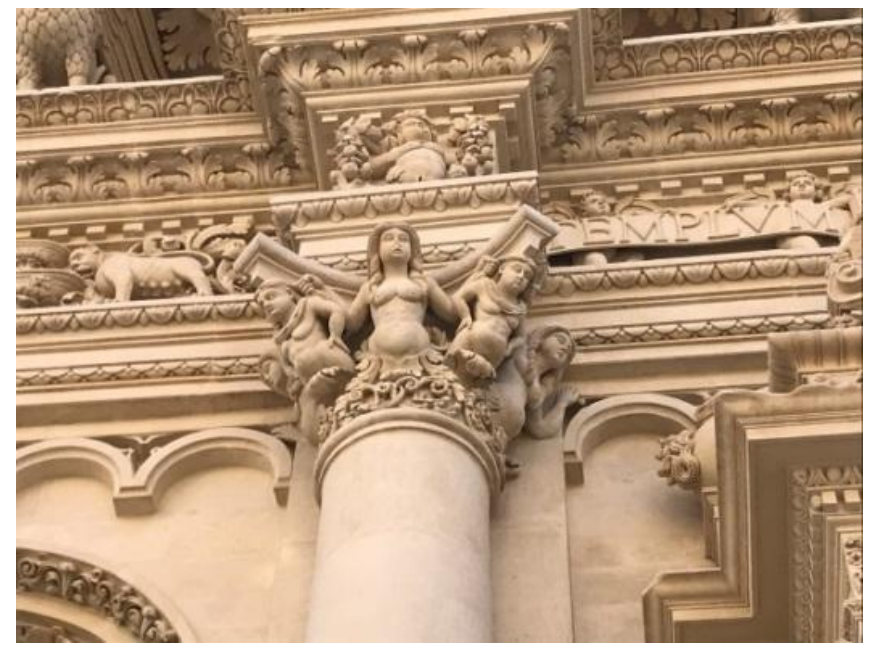

Res. 1: Basilica di Santa Croce ( Kutsal Haç Bazilikası), Sütun Başlığı Detayı.

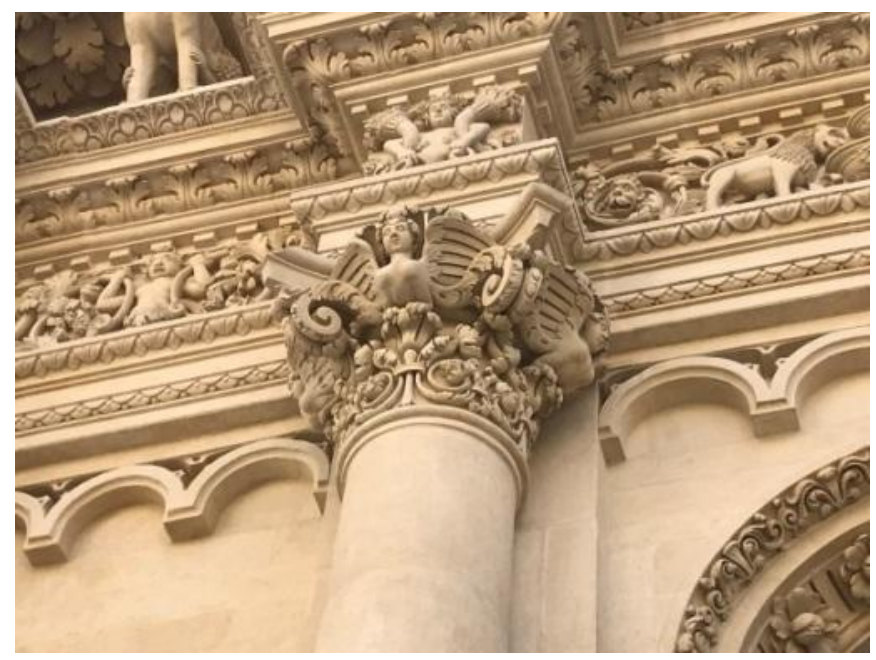

Res. 2: Basilica di Santa Croce ( Kutsal Haç Bazilikası), Sütun Başlığı Detayı. 


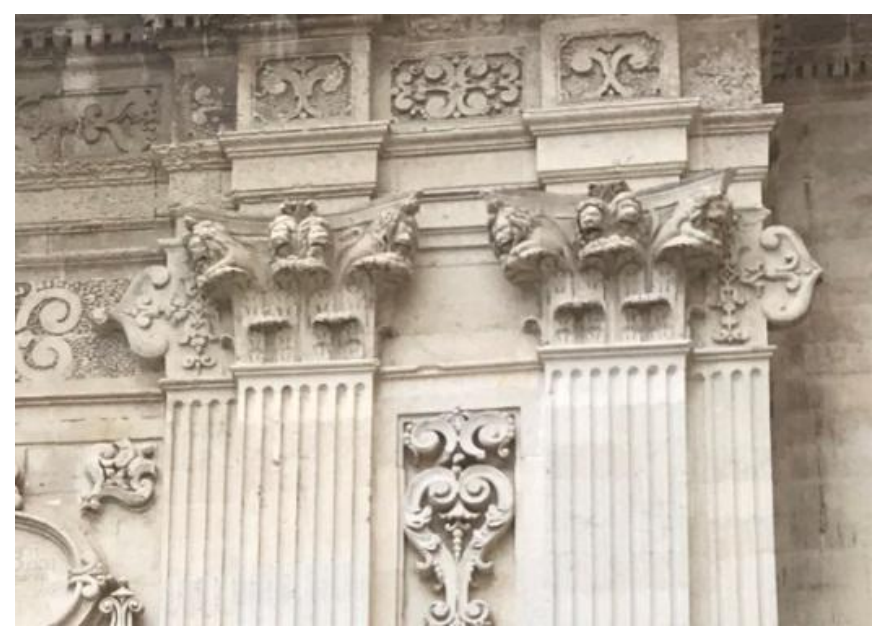

Res. 3: Duomo di Lecce (Lecce Katedrali), Sütun Başlığı Detayı.

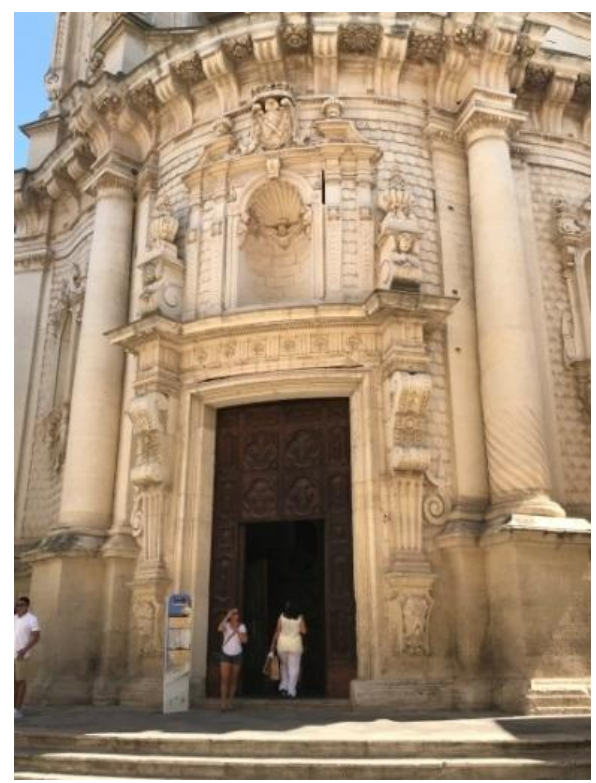

Res. 4: Chiesa di San Matteo (Aziz Matta Kilisesi), Estipite Sütun.

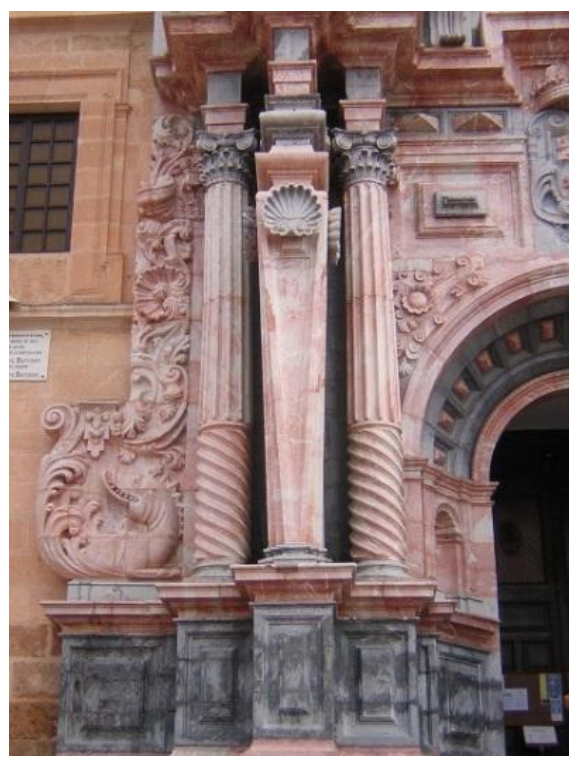

Res. 5: Caravaca de La Cruz Bazilikas1, Estipite Sütun. 


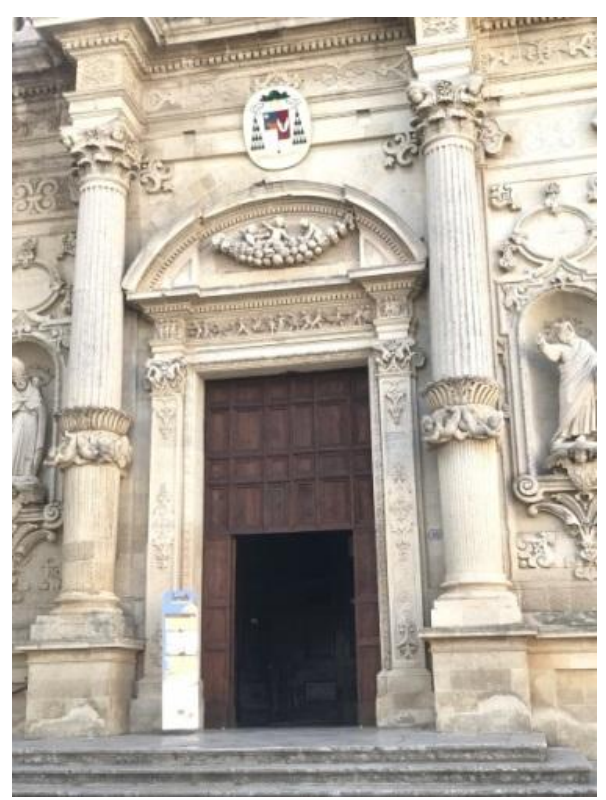

Res. 6: Duomo di Lecce (Lecce Katedrali), Kuzey Cephe Portali.

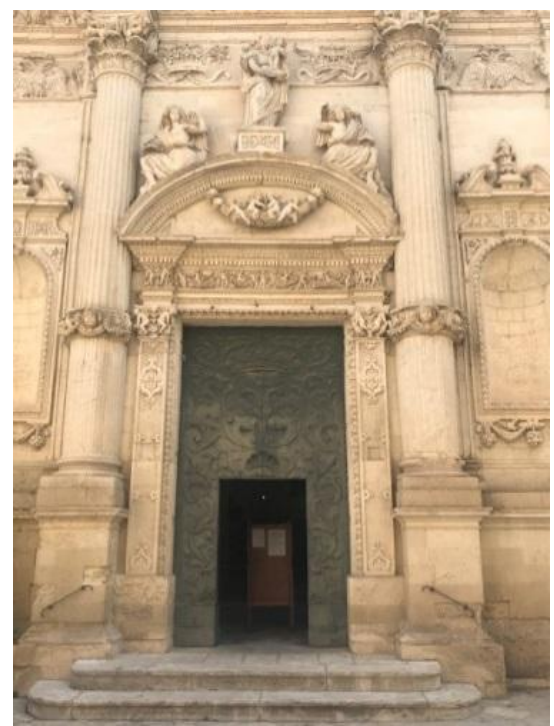

Res. 7: Chiesa di Sant'Angelo o di Santa Maria di Costantinopoli (Aziz Angelo ya da İstanbul'un Kutsal Meryem'i Kilisesi), Batı Cephe Portali. 


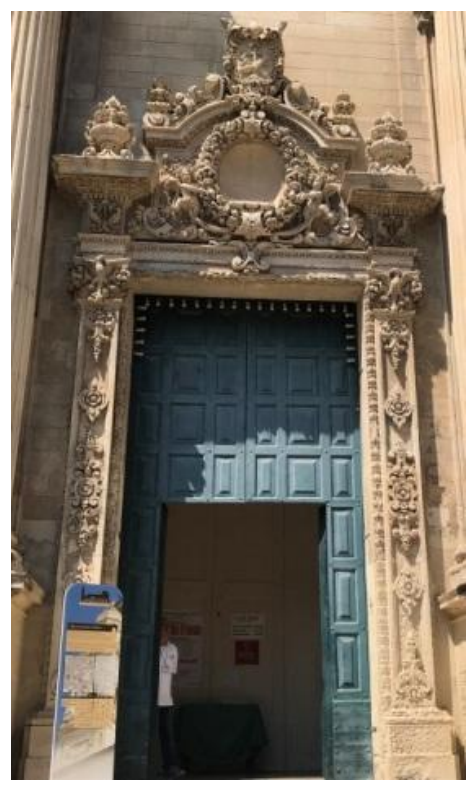

Res. 8: Chiesa di Santa Chiara (Azize Chiara Kilisesi), Batı Cephe Portali.

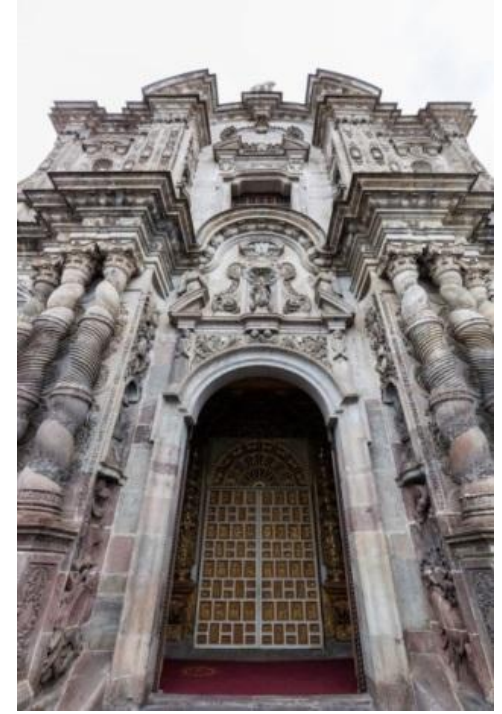

Res. 9: La Compania de Jesus Kilisesi, Portal.

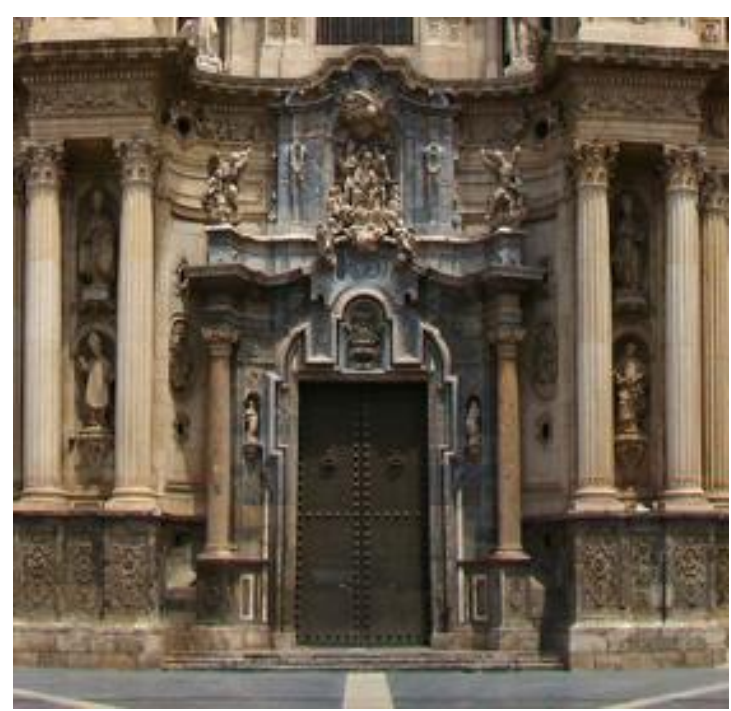

Res. 10: Murcia Katedral, Portal. 


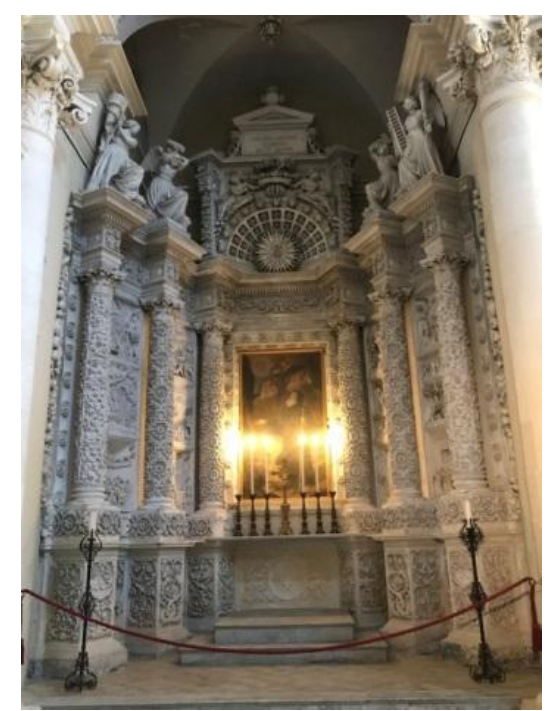

Res. 11: Basilica di Santa Croce (Kutsal Haç Bazilikası), “Aziz Francesco di Paola Şapeli.

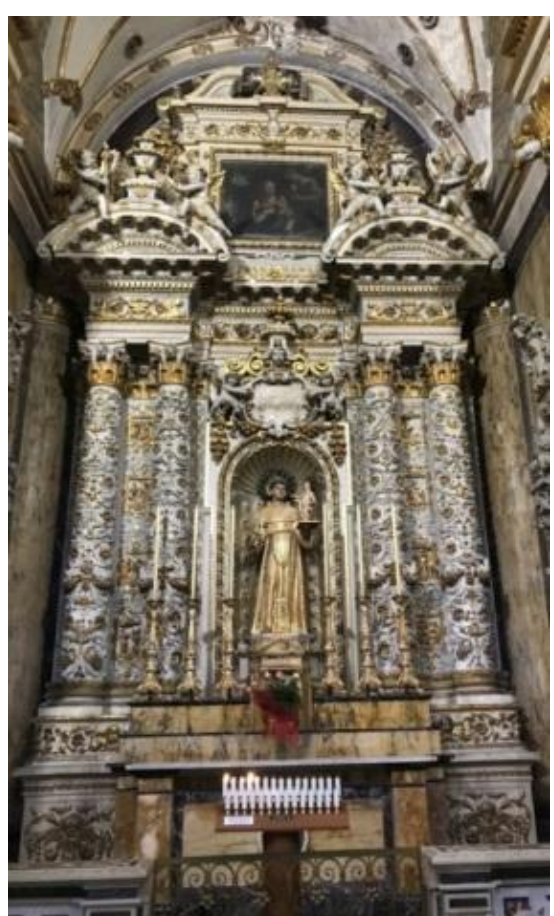

Res. 12: Duomo di Lecce (Lecce Katedrali), Aziz Antonio da Padova Şapeli. 


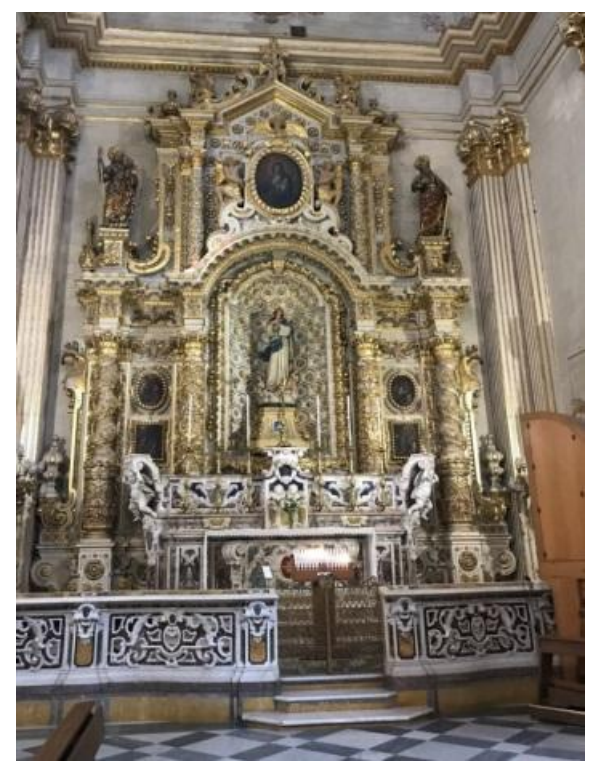

Res. 13: . Duomo di Lecce (Lecce Katedrali), Meryem'in Günahsız Gebeliği Şapeli.

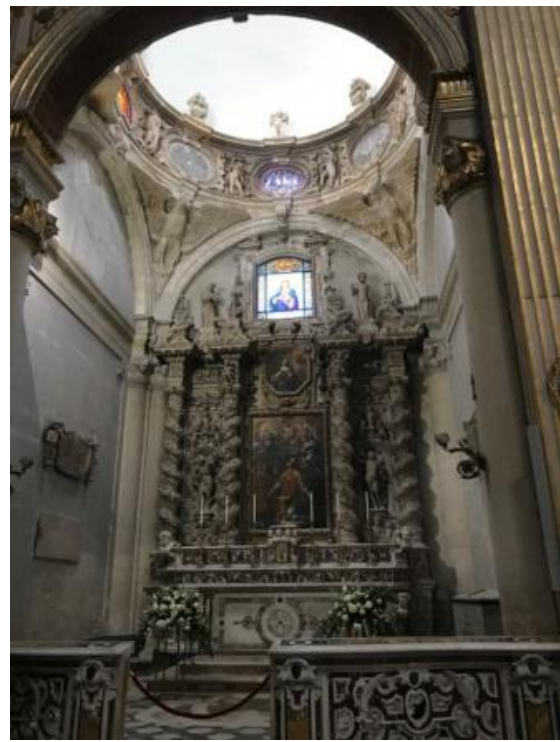

Res. 14: Duomo di Lecce (Lecce Katedrali), Aziz Filippo Neri Şapeli.

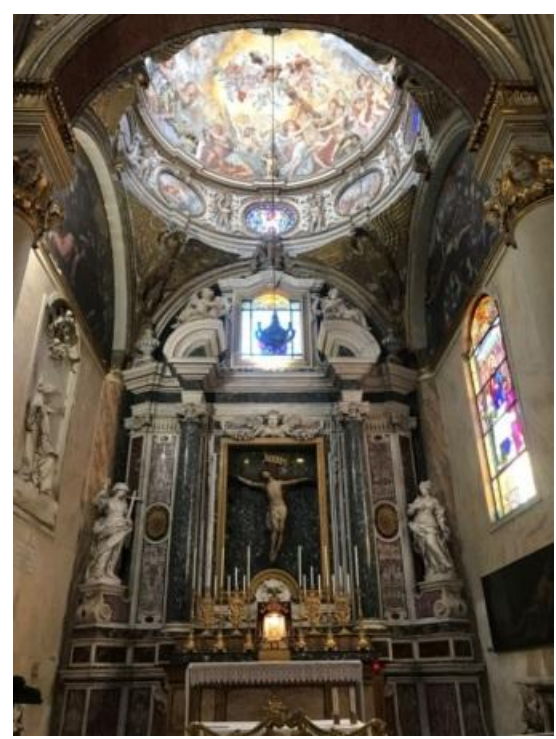

Res. 15: Duomo di Lecce (Lecce Katedrali), Haç Şapeli. 


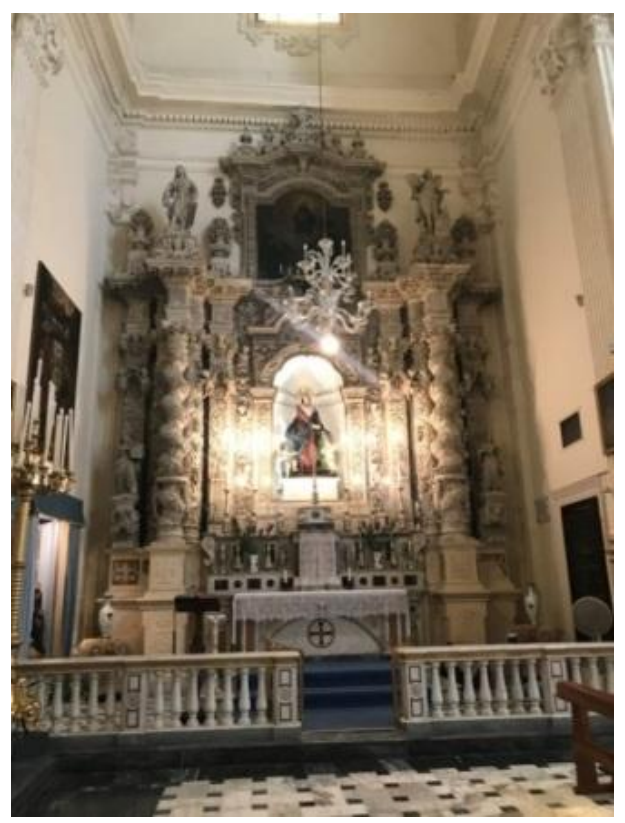

Res. 16: Chiesa di Sant'Angelo o di Santa Maria di Costantinopoli (Aziz Angelo ya da İstanbul'un Kutsal Meryem'i Kilisesi), Üzgün Meryem Şapeli.

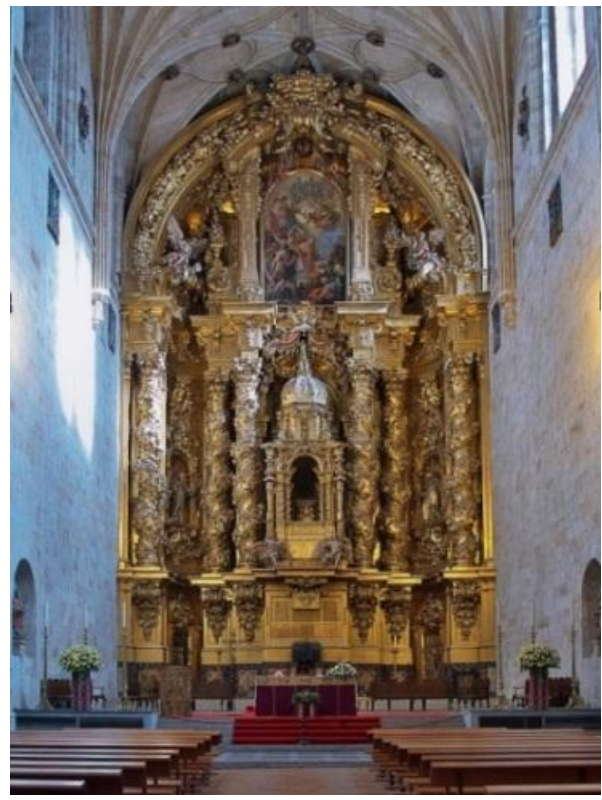

Res. 17: San Esteban Manastır, Şapel. 


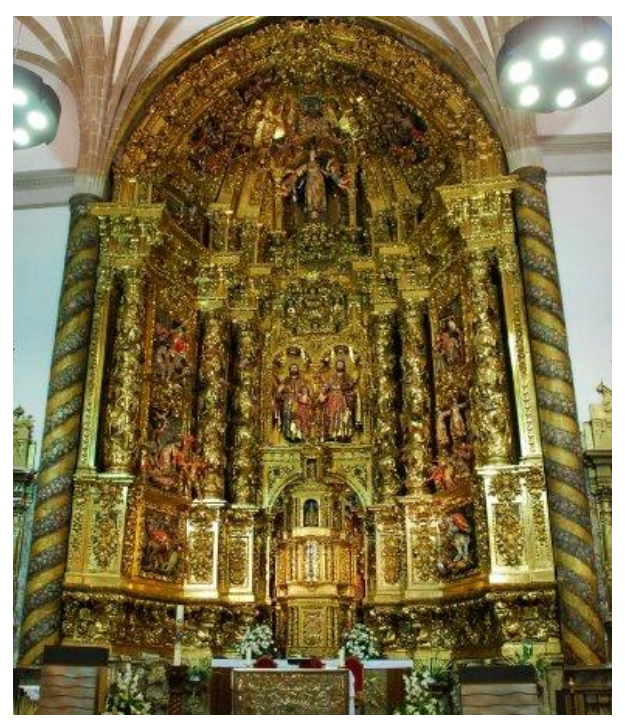

Res. 18: San Cosme y San Damian de Arnedo, Şapel.

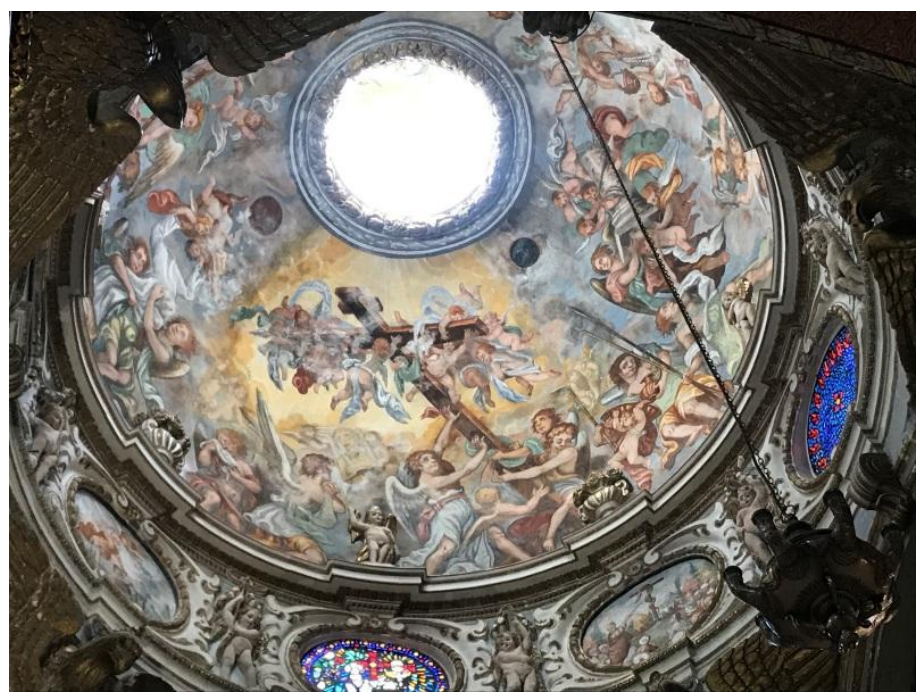

Res. 19: Duomo di Lecce (Lecce Katedrali), Haç Şapeli Kubbe Detayı. 